\title{
Spectrophotometric Analysis of Saliva for Metal Ion Release in Patients Prior to and After Cementation of Cobalt Chromium or Nickel-Chromium Alloy Crowns: An in Vivo Study
}

\author{
${ }^{1}$ Bhoomi A Parmar, ${ }^{2}$ Jyoti B Nadgere, ${ }^{3}$ Sabita M Ram, ${ }^{4}$ Naisargi P Shah
}

\section{ABSTRACT}

Aim: This study aimed to spectrophotometrically analyze saliva for metal ion release in patients prior to and post cementation of either cobalt chromium or nickel-chromium alloy crowns-In vivo.

Materials and methods: Twenty participants selected, divided into two groups, each group having 10 participants, Group 1 - Cobalt chromium crown fabrica ted and cemented and Group 2-Nickel-chromium crown fabricated and cemented. Saliva was collected before cementation of the crown and 1st day, 7 th day and 15th day after cementation of the crown and subjected to spectrophotometric analysis by atomic absorption spectrophotometer.

Results: The statistical analysis showed that there were no traces found of cobalt and chromium ions in the sample of Group 1 participants before cementation of the crown. After cementation of cobalt chromium crown traces of cobalt and chromium were found on Days 1, 7 and 15. The traces were found on 1st day which increased on Day 7 and then a decline was observed in the number of ions on Day 15.

In Group 2, no traces were found of nickel and chromium ions in samples of participants before cementation of the crown. After cementation of nickel chromium crown traces of nickel and chromium were found on Days 1, 7 and 15. The traces of ions were found on Day 1 which increased by Day 7 and then a decline was observed in the number of ions on day 15 .

Conclusion: The results showed that compared to Group 1 the release of metal ions was found to be more in Group 2.

Keywords: Cobalt chromium, Metal ion release, Nickel-chro mium

\footnotetext{
${ }^{1}$ Postgraduate student, ${ }^{2-4}$ Professor

${ }^{1-4}$ Department of Prosthodontics and Crown and Bridge, Mahatma Gandhi Missions's Dental College and Hospital, Navi Mumbai, Maharashtra, India

Corresponding Author: Bhoomi A. Parmar, Department of Prosthodontics and Crown and Bridge, Mahatma Gandhi Missions's Dental College and Hospital, Navi Mumbai, Maharashtra, India, Phone: +918425042991, E-mail: bhoomiparmar21@gmail.com
}

How to cite this article: Parmar BA, Nadgere JB, Ram SM, Shah NP. Spectrophotometric Analysis of Saliva for Metal Ion Release in Patients Prior to and After Cementation of Cobalt Chromium or Nickel-Chromium Alloy Crowns: An in Vivo Study. J Contemp Dent 2018;8(2):92-96.

Source of support: Nil

Conflict of interest: None

\section{INTRODUCTION}

Metals are an integral part of dentistry. The two most commonly used base metal alloys are cobalt chromium and nickel-chromium alloys. The biocompatibility of dental alloys used in dental restorations is a critical issue because these materials are in intimate contact with oral tissues for long terms and can not be removed by the patient. The placement of a material into the oral cavity creates active interfaces through which the body affects the material and the material affects the body. ${ }^{1}$

Corrosion of alloys occurs when elements in the alloy ionize. Thus, the elements that were initially uncharged inside the alloy lose electrons and become positively charged ions as they are released into solution. The oral environment, not only includes the process of destruction and dissolution in saliva but also chemical/physical destruction, wear, and erosion caused by food, chewing and bacterial activity. ${ }^{2}$

Various studies have been carried out in vitro to assess the release of ions; however, in vivo studies for recording the release of ions into the saliva are scant and data of the metal content measurements of saliva are lacking. Hence in vivo study for the release of metal ions from metal crowns fabricated with Cobalt-chromium and nickel-chromium need to be evaluated. ${ }^{3}$

\section{MATERIALS AND METHODS}

Twenty participants requiring full metal crown were selected. Participants were divided into two groups, each group having 10 participants: Group 1-Cobalt chromium crown fabrica ted and cemented in participants, 
and, Group 2-Nickel-chromium crown fabricated and cemented in participants.

Unstimulated saliva was collected in sterile polypropylene tubes prior to preparation of crown for spectrophotometric analysis.

All the saliva samples were collected in the morning, and the participants were advised to refrain from intake of any food or beverage (water exempted) one hour before the test session. Chewing gum and intake of coffee was also prohibited during this hour. The participants were advised to rinse his or her mouth with $15 \mathrm{~mL}$ deionized and distilled water for 30 seconds and then to relax for half an hour. The participant was then asked to swallow to void the mouth of saliva. The participant was instructed to seat erect and let the saliva collect in his or her mouth. The saliva was then aspirated with a sterile $5 \mathrm{ml}$ needless syringe $\mathrm{e}^{3,4} 5 \mathrm{~mL}$ of saliva was collected. The saliva then was transferred to a polypropylene tube and secured with rubber stops. The collected was saliva sample was then within an hour carried to the laboratory. The saliva sample was placed at room temperature. As the study is concerned with the inorganic matter there is no effect of room temperature on it, hence the saliva sample before being taken to the laboratory was placed at room temperature.

Tooth preparation for receiving full metal crown restoration was done following the biomechanical principles. Full metal crowns were cemented as per assigned groups. Saliva samples were collected on Days 1, 7 and 15 in a similar procedure as done prior to tooth preparationfor spectrophotometric analysis.

The atomic absorption spectrophotometer analyzed the saliva samples from Groups 1 and 2.

For Groups 1 and 2 patients, after collection of the saliva according to the assigned time the sample was transferred to a conical flask and digested on a hot plate with $5 \%$ of $\mathrm{HNO} 3$ for one hour. After dry-up, 5\% $\mathrm{HNO}_{3}$ was added to make up $100 \mathrm{~mL}$ volume.

The sample was then subjected to atomic absorption spectrophotometer for analysis of:

Group 1: Ni and Cr metal ions

Group 2: Co and Cr metal ions.

\section{Cobalt Analysis}

The atomic absorption spectrophotometer was calibrated the sample solution was aspirated with pipette and absorbance was measured at $240.7 \mathrm{~nm}$ wavelength.

\section{Chromium Analysis}

The atomic absorption spectrophotometer was calibrated the sample solution was aspirated with pipette and absorbance was measured at $357.9 \mathrm{~nm}$ wavelength.

\section{Nickel Analysis}

The atomic absorption spectrophotometer was calibrated and the sample solution was aspirated with pipette and absorbance was measured at $232.0 \mathrm{~nm}$ wavelength.

The values, then obtained for Group 1 and 2 were tabulated and subjected to statistical analysis.

\section{RESULTS}

Metallic ion release from Groups 1 and 2 was described in the form of mean and standard deviation. Two types of metal ions released from Group 1 were analyzed during the study period: cobalt $(\mathrm{Co})$, chromium $(\mathrm{Cr})$. Two types of metal ion released from Group 2 were analyzed during the study period: nickel (Ni), chromium $(\mathrm{Cr})$.

In Group 1, after cementation of cobalt chromium crowns the mean value for the release of cobalt was maximum on Day 7 (0.1562 ppm \pm 0.09353 SD), and the minimum was on Day 15 (0.0826 \pm .05944 SD) (Table 1 and Graph 1). The mean value for the release of chromium was maximum on Day 7 (0 .1221 \pm .14496 SD), and the minimum was on day 15 (0. $0174 \pm .00955$ SD) (Table 2 and Graph 2).

Table 1: Comparison of changes in cobalt metal ion levels on different time intervals for Group 1

\begin{tabular}{lllll}
\hline $\begin{array}{l}\text { Time } \\
\text { interval }\end{array}$ & Mean & $N$ & $\begin{array}{l}\text { Std. } \\
\text { deviation }\end{array}$ & $\begin{array}{l}\text { Std. error } \\
\text { mean }\end{array}$ \\
\hline Control & 0.0000 & 10 & 0.00000 & 0.00000 \\
Day 1 & 0.1138 & 10 & 0.06382 & 0.02018 \\
Day 7 & 0.1562 & 10 & 0.09353 & 0.02958 \\
Day 15 & 0.0826 & 10 & 0.05944 & 0.01880 \\
\hline
\end{tabular}

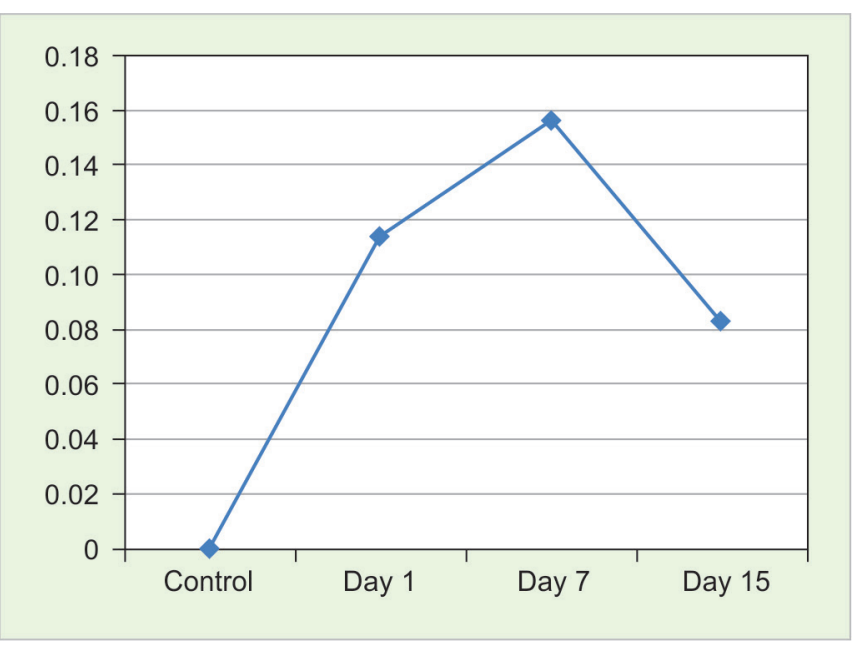

Graph 1: The cobalt ion release for Group 1 participants at various time intervals 
Table 2: Comparison of change in chromium metal ion levels on different time intervals for Group 1.

\begin{tabular}{lllll}
\hline $\begin{array}{l}\text { Time } \\
\text { interval }\end{array}$ & Mean & $N$ & $\begin{array}{l}\text { Std. } \\
\text { deviation }\end{array}$ & $\begin{array}{l}\text { Std. error } \\
\text { mean }\end{array}$ \\
\hline Control & 0.0000 & 10 & 0.0000 & 0.0000 \\
Day 1 & 0.0456 & 10 & 0.06020 & 0.01904 \\
Day 7 & 0.1221 & 10 & 0.14496 & 0.04584 \\
Day 15 & 0.0174 & 10 & 0.00955 & 0.00302 \\
\hline
\end{tabular}

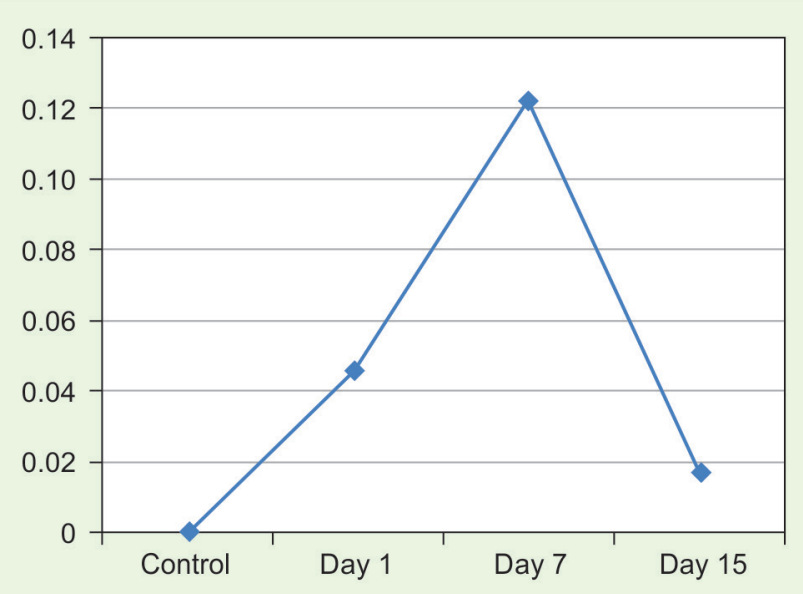

Graph 2: The chromium ion release for Group 1 participants at various time intervals

In Group 2, after cementation of nickel chromium crowns the mean value for the release of nickel was maximum on day $7(0.3993 \pm 0.13072 \mathrm{SD})$ and the minimum was on day $15(0.1374 \pm 0.04858$ SD) (Table 3 and Graph 3). The mean value for the release of chromium was maximum on day $7(0.1268 \pm 0.3428 \mathrm{SD})$ and the minimum was on day $15(0.0411 \pm 0.00782 \mathrm{SD})$ (Table 4 and Graph 4).

Table 3: Comparison of change in nickel metal ion levels on different time intervals for Group 2

\begin{tabular}{lllll}
\hline $\begin{array}{l}\text { Time } \\
\text { interval }\end{array}$ & Mean & $N$ & $\begin{array}{l}\text { Std. } \\
\text { deviation }\end{array}$ & $\begin{array}{l}\text { Std. error } \\
\text { mean }\end{array}$ \\
\hline Control & 0.0000 & 10 & 0.0000 & 0.0000 \\
Day 1 & 0.1981 & 10 & 0.06631 & 0.02097 \\
Day 7 & 0.3993 & 10 & 0.13072 & 0.04134 \\
Day 15 & 0.1374 & 10 & 0.04858 & 0.01536 \\
\hline
\end{tabular}

Table 4: Comparison of change in chromium metal ion levels on different time intervals for Group 2.

\begin{tabular}{lllll}
\hline $\begin{array}{l}\text { Time } \\
\text { interval }\end{array}$ & Mean & $N$ & $\begin{array}{l}\text { Std. } \\
\text { deviation }\end{array}$ & $\begin{array}{l}\text { Std. error } \\
\text { mean }\end{array}$ \\
\hline Control & 0.0000 & 10 & 0.00000 & 0.00000 \\
Day 1 & 0.0797 & 10 & 0.02320 & 0.00734 \\
Day 7 & 0.1268 & 10 & 0.03428 & 0.01084 \\
Day 15 & 0.0411 & 10 & 0.02474 & 0.00782 \\
\hline
\end{tabular}

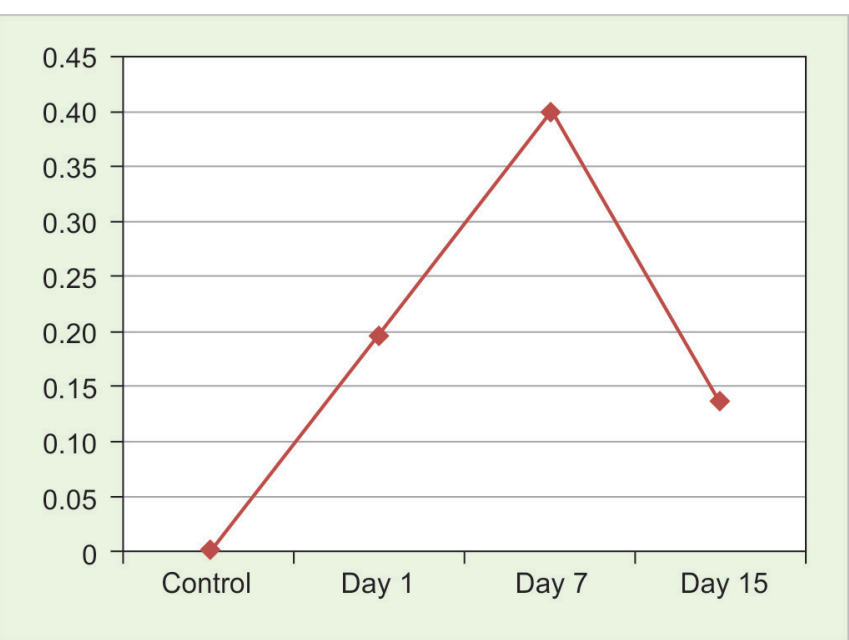

Graph 3: The nickel ion release for Group 2 participants at various time intervals

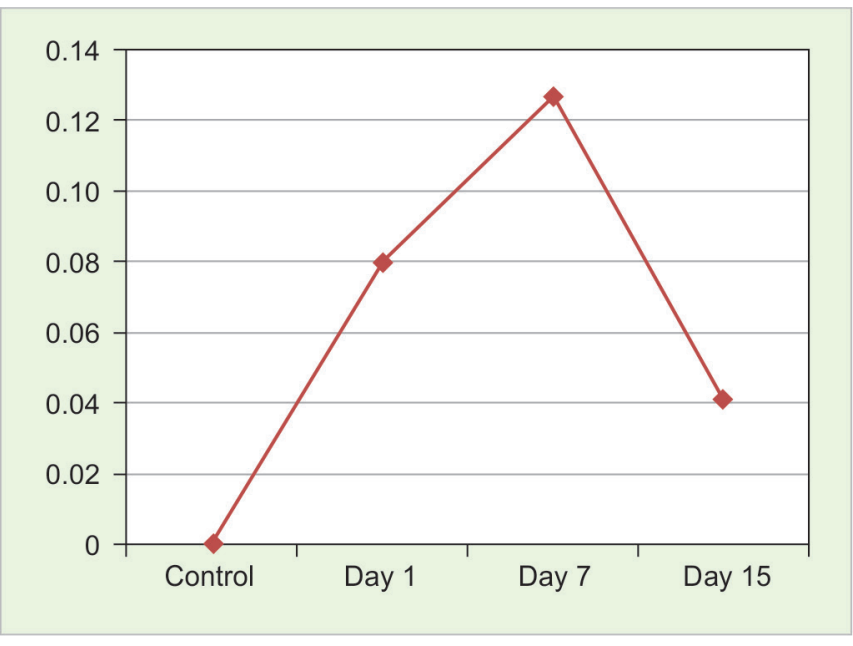

Graph 4: The chromium ion release for Group 2 participants at various time intervals

Comparison of the release of chromium ions on Days 1, 7 and 15 between Groups 1 and 2 using independenttest revealed that comparison was statistically significant $(\mathrm{p}>0.05)$, indicates the average score is significantly more in Group 2 than Group 1 (Table 5 and Graph 5).

Comparison of the release of cobalt chromium ions and nickel chromium ions on Days 1, 7 and 15 between Groups 1 and 2 using independent-test revealed that comparison was statistically significant $(\mathrm{p}<0.05)$, indicates the average score is significantly more in Group 2 than Group 1 (Table 6 and Graph 6).

Table 5: Analysis of variance (independent t-test) for comparison of concentration of chromium metal ions at different time intervals for Groups 1 and 2

\begin{tabular}{lllll}
\hline Days & $T$ & Df & $\begin{array}{l}\text { Sig. } \\
(2 \text {-tailed) }\end{array}$ & $\begin{array}{l}\text { Mean } \\
\text { difference }\end{array}$ \\
\hline Day 1 & -1.670 & 18 & 0.112 & -0.03408 \\
Day 7 & -.099 & 18 & 0.922 & -0.00466 \\
Day 15 & -2.828 & 18 & 0.011 & -0.02372 \\
\hline
\end{tabular}




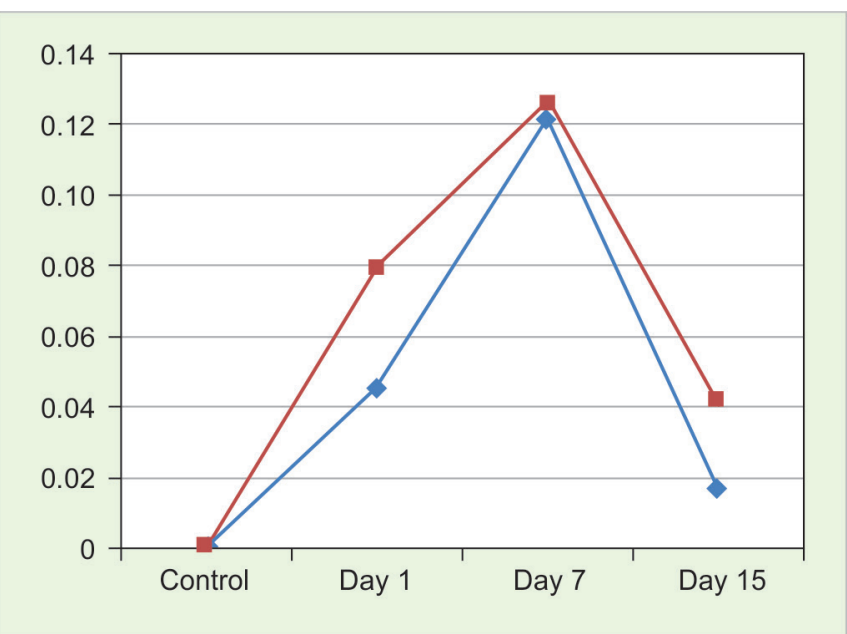

Graph 5: The comparison of chromium ion release from Group 1 and Group 2 participants at various time intervals

Table 6: Analysis of variance (independent t-test) for comparison of concentration of cobalt chromium ions and nickel chromium ions at different time intervals for Groups 1 and 2

\begin{tabular}{lllll}
\hline $\begin{array}{l}\text { Time } \\
\text { interval }\end{array}$ & $T$ & Df & $\begin{array}{l}\text { Sig. } \\
\text { (2-tailed) }\end{array}$ & $\begin{array}{l}\text { Mean } \\
\text { Difference }\end{array}$ \\
\hline Day 1 & -2.536 & 38 & 0.015 & -0.05919 \\
Day 7 & -2.684 & 38 & 0.011 & -0.12389 \\
Day 15 & -2.148 & 38 & 0.038 & -0.03926 \\
\hline
\end{tabular}

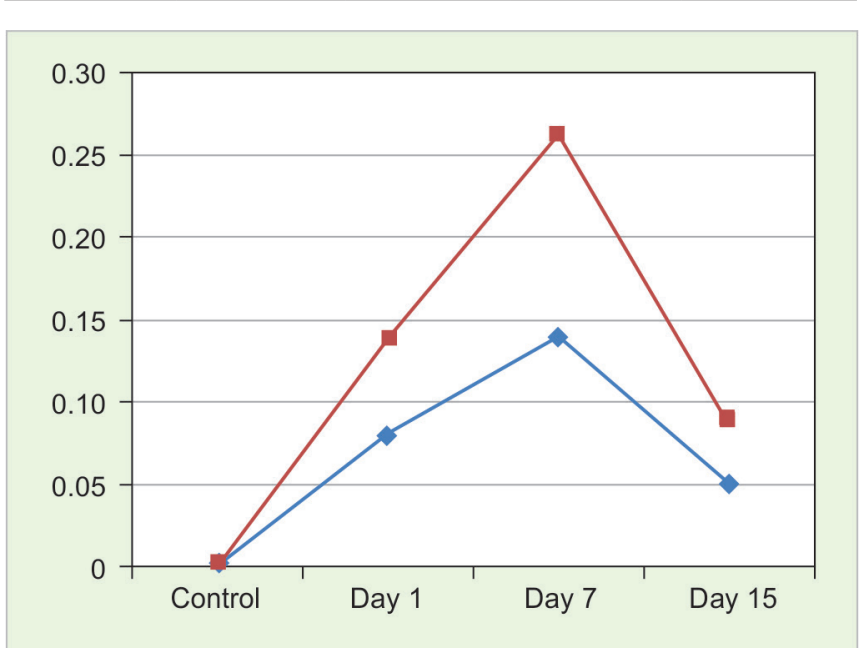

Graph 6: Comparison of release of cobalt chromium ions and nickel chromium ions in Groups 1 and 2 at various time intervals

\section{DISCUSSION}

Various types of alloys are available in dentistry to be used for crown and bridge. In developing countries, base metal alloys are more popularly advised. However, the common decisive factor for all these materials is the permanent survival of them in the oral cavity for a prolonged time without the ability to be removed by the patient. Therefore, knowledge about the elemental release from these materials into the oral cavity is of great importance. The biocompatibility of dental alloys used in fixed prosthodontics is a critical issue because these materials are in intimate contact with oral tissues for long terms and cannot be removed by the patient. ${ }^{1}$

Irrespective of the material placed, these interactions occur depending on the material, the host, the masticatory forces and conditions placed on the material. ${ }^{5}$ Nickel-chromium alloys are not as thermodynamically stable, and a major aspect of their corrosion resistance is related to the formation of a thin, protective oxide film on the metal surface, which is a passive film. If the oxide film is disrupted, then the metal or alloy must re-passivate in order for the material to be protected ${ }^{6}$. Nickel-chromium alloys show unstable galvanic corrosion behavior.?

Fisher stated that nickel is one of the most common causes of allergic contact dermatitis, especially in women. ${ }^{8}$ The average dietary intake of nickel 200 to 300 $\mu \mathrm{g} /$ day, chromium 50 to $200 \mu \mathrm{g} /$ day and cobalt $250 \mu \mathrm{g} /$ day. ${ }^{9}$

Cobalt is an essential element for life in small quantities. Median lethal dose (LD50) values of soluble cobalt salts have been found to be between 150 and 500 $\mathrm{mg} / \mathrm{kg}$. The prevalence of nickel sensitivity in the general population has been estimated to range from 6.7 to $17.5 \%$. It has been recommended that patients who are highly sensitive should not exceed a nickel concentration intake threshold of $0.06 \mathrm{mg} / \mathrm{l}$.

Next to nickel and chromium, cobalt is a major cause of contact dermatitis and is carcinogenic. However, in the present in vivo study the release of cobalt, chromium and nickel ions from Groups 1 and 2 were within the physiological limit. ${ }^{10}$

Many in vitro studies have been performed for investigation of metal ions released from dental cast alloys. But in the oral environment, this includes not only the process of destruction and dissolution in saliva but also chemical/physical destruction, wear and erosion caused by food, chewing and bacterial activity. Biting stresses on prosthesis can be tremendously great, and temperatures fluctuation may between $25^{\circ}$ $\mathrm{C}$ and $45^{\circ} \mathrm{C}$ and $\mathrm{pH}$ may change instantaneously from acidic to alkaline. ${ }^{11}$ The metal ions leaching from the dental material have been attributed to be the main cause for allergic or inflammatory reaction, these metal ions released from metal alloys are carried to the oral cavity or transported to the gastrointestinal tract after being swallowed. ${ }^{12}$ Thus, it is imperative to evaluate the material reactivity in the oral cavity, which is governed by thermodynamic principles and electrochemical reaction kinetics.

According to the values obtained in Group 1 both the cobalt and chromium reaches a peak level on the Day 7 then the rate of release diminishes with time. Also with the Group 2 the nickel and chromium reach 
a peak level on the 7th day then the rate of release of nickel and chromium diminishes with time. Both nickel and chromium release reaches a peak level on the 7th day, then the rate of release diminishes with time. The possible explanation would be if cobalt chromium for Group 1 and nickel chromium for Group 2 may be present on the surface of the crowns during the first 7 days, then the rate of release drops as the surface cobalt chromium and nickel chromium is depleted. ${ }^{13}$

\section{CONCLUSION}

There was a release of metal ions observed from both the groups. The release of ions from Group 2 was more as compared to Group 1. The clinician should decide which material to used keeping this in mind and further longterm studies should be planned.

\section{REFERENCES}

1. W. Elshahawy, I. Watanabe. Biocompatibility of dental alloys used in dental fixed prosthodontics. Tanta Dental Journal. 2014;11:150-159.

2. Wataha JC. Biocompatibility of dental casting alloys: A review. J Prosthet Dent. 2000;83:223-34.

3. P. Garhammer, K.A.Hiller, T. Reitinger, G. Schmalz. Metal content of saliva of patients with and without metal restoration. Clin Oral Invest. 2004;8:238-242.
4. Covington JC, McBride MA, Slagle WF, Disney AL. Quantization of nickel and beryllium leakage from base metal casting alloys. J Prosthet Dent. 1985; 54:127-36.

5. Wataha JC, Messer RL. Casting alloys. Dent Clin North Am 2004;48:499-512.

6. Taher NM, Al Jabab AS. Galvanic corrosion behavior of i mplant suprastructure dental alloys. Dent Mater. 2003;19:5459.

7. Covington JC, McBride MA, Slagle WF, Disney AL. Quantization of nickel and beryllium leakage from base metal casting alloys. J Prosthet Dent 1985;54:127-136.

8. Bhaskar V, Subba Reddy. Biodegradation of nickel and chromium from space maintainers: An in vitro study. J Indian SocPedod Prevent Dent. 2010;28:6-12.

9. Barceloux DG. Nickel. JClinToxicol. 1999; 37:239-258.

10. Basketter DA, Angelini G, Ingber A, Kern PS, Menné T. Nickel, chromium and cobalt in consumer products: revisiting safe levels in the new millennium. Contact Dermatitis. 2003;49: $1-7$.

11. Lygre H, Solheim E, Gjerdet NR, Berg E. Leaching of organic additives from dentures in vivo. ActaOdontolScand. 1993; 51:45-51.

12. Baker S, Brooks SC, Walker DM. The release of residual monomeric methyl methacrylate from acrylic appliances in the human mouth: An assay for monomer in saliva. J Dent Res. 1988;67:1295-1299.

13. Wataha JC, Lockwood PE. Release of elements from dental casting alloys into cell-culture medium over 10 months. Dent Mater. 1998;14:158-163. 